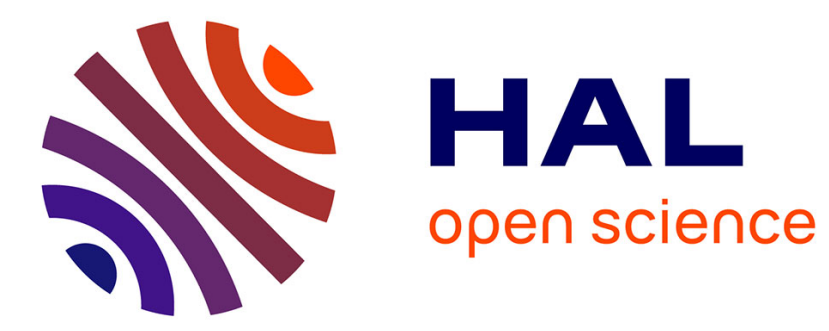

\title{
A versatile simulator for defrosting, convective and boiling drying during hot air frying process
}

Daniel Goujot, Têko Gouyo, Philippe Bohuon, Francis Courtois

\section{To cite this version:}

Daniel Goujot, Têko Gouyo, Philippe Bohuon, Francis Courtois. A versatile simulator for defrosting, convective and boiling drying during hot air frying process. International Multidisciplinary Modeling \& Simulation Multiconference, Sep 2021, Krakow, Poland. hal-03320803

\section{HAL Id: hal-03320803 \\ https: / hal.inrae.fr/hal-03320803}

Submitted on 16 Aug 2021

HAL is a multi-disciplinary open access archive for the deposit and dissemination of scientific research documents, whether they are published or not. The documents may come from teaching and research institutions in France or abroad, or from public or private research centers.
L'archive ouverte pluridisciplinaire HAL, est destinée au dépôt et à la diffusion de documents scientifiques de niveau recherche, publiés ou non, émanant des établissements d'enseignement et de recherche français ou étrangers, des laboratoires publics ou privés. 
$33^{\text {rd }}$ European Modeling \& Simulation Symposium

$18^{\text {th }}$ International Multidisciplinary Modeling \& Simulation Multiconference

2724-0029 (C) 2020 The Authors.

doi: $\mathrm{xx} . \mathrm{xxxx} / \mathrm{xxxx}$

\title{
A versatile simulator for defrosting, convective and boiling drying during hot air frying process
}

\author{
Daniel Goujot ${ }^{1, *}$, Têko Gouyo ${ }^{2,3}$, Philippe Bohuon² and Francis Courtois ${ }^{2}$ \\ ${ }^{1}$ Université Paris-Saclay, INRAE, AgroParisTech, UMR SayFood, 1, avenue des Olympiades, Massy, 91300, France \\ ${ }^{2}$ QualiSud, Univ Montpellier, Avignon Université, CIRAD, Institut Agro, IRD, Université de La Réunion, 73 Rue \\ Jean François Breton, Montpellier, 34090, France \\ ${ }^{3}$ SEB, Ecully-Food Science; 112 Chemin du Moulin Carron, Écully, 69130, France \\ * Email address: daniel.goujot@agroparistech.fr
}

\begin{abstract}
A versatile simulator takes into account four major stages: defrosting, warm-up, and convective and boiling drying. This dynamic model considers that a frozen prefried french fries has three compartments: a central compartment (\#1) with high water content, a peripheral compartment (\#3) corresponding to the prefried dry crust, and an intermediate compartment (\#2) appears during frying, filled with water vapour. Convective and boiling drying and freezing are modeled. The predicting model has been identified based on the triplicates of three different modalities. The resulting predictions have been experimentally validated.
\end{abstract}

Keywords: Frying; Modelling; Heat transfer; French fries; Mass transfer

\section{Introduction}

Gouyo et al. (2021b) published results of X-ray microtomography showing that prefried frozen French fries have a moist and soft core, and a crispy outer dry crust of approximately $0.5-1.5 \mathrm{~mm}$ (Bouchon and Aguilera, 2001; Pedreschi and Aguilera, 2002). French fries are popular potato products because of their structure and attractive texture (Garayo and Moreira, 2002). Deep-fat frying can be defined as a process of drying and cooking through contact with hot oil. This process essentially consists of soaking the product in hot vegetable oil at a temperature above the boiling point of water, typically $150-180^{\circ} \mathrm{C}$. These frying conditions lead to high rates of heat and mass transfer, causing water loss and oil uptake, with consequent changes in taste, texture and colour properties.

Two disadvantages of consuming deep-fat fries, and in general all deep-fat fried products, is related to their high fat content (about $20-40 \mathrm{~g}$ oil $/ 100 \mathrm{~g}$ fat-free dry matter) (Garayo and Moreira, 2002) and to the time it takes to fry them.

Hot-air fryers, recently developed, prevent the high oil uptake during fries. The objective is to reduce oil uptake when consuming french fries. The hot-air frying aims to produce a "fried product" by sparging, essentially, hot-air around the material instead of immersing it in hot oil (Andrés et al., 2013; Heredia et al., 2014; Sansano et al., 2015; Teruel et al., 2015; Tian et al., 2017). Their hot air bring surface of french fries to the boiling point, creating a fine mist of oil droplets in hot-air and the product. They may combine forced convection, radiation, and/or conduction.

The structure of the core and of the crust of a frying product is affected by the temperature kinetics and the process. Therefore, a better understanding of the heat and mass transport is a useful step to improve hot-air fries. This understanding will be based on a mathematical model, based on fundamental physical principles.

(C) 2021 The Authors. This article is an open access article distributed under the terms and conditions of the Creative Commons Attribution (CC BY-NC-ND) license (https://creativecommons.org/licenses/by-nc-nd/4.0/). 
The aim of this work is a dynamic model for the hotair frying of frozen pre-fried french fries, simulating both heat and mass transfer.

\section{State of the art of frying models}

Various models have been developed to describe deepfat frying in the past. However, the changes occurring during frying are difficult to model, as several interdependent factors must be taken into account. It is important to identify the structural changes during the different stages of the process in order to understand the quality changes that occur during frying. The mechanism of water loss during frying is complex and transport by molecular diffusion, capillary and pressure are often considered. The complexity ranges from simple empirical equations to complex numerical models. All models have their own advantages in describing the water loss during frying.

A first-order kinetic model in which water loss was proportional to moisture content was considered by Gupta et al. (2000) and Krokida et al. (2001). These models consider the frying material (usually very thin products such as chips), as a single zone in which the presence of crust is neglected. The single zone model explains the heat and mass transfer equations for the entire product without considering the difference between the core and the crust.

Models with two concentric comparments were also used (Farkas et al., 1996; Farid and Chen, 1998; Bouchon and Pyle, 2005). The crust and core are treated as two regions separated by a moving boundary (front model) and a pressurized flow in the crust region is included. Each region evolves during frying, the crust thickens and the core thickness decreases. In each region, simultaneous heat and mass transfer occurs, resulting in thermal and water content gradients.

We also find in the literature multiphase porous media models (Xiong et al., 1992; Ni and Datta, 1999; Yamsaengsung and Moreira, 2002) and compartmental dynamic models (Courtois et al., 1998; Costa and Oliveira, 1999) to describe deepfat frying. All these models take into account the latent heat of vaporization and the heat transport, but the transfer of matter by entrainment is often neglected. From the point of view of the boundary conditions a constant $h_{c}$ coefficient is often used. Similar approaches to frying models are generally used in the process of entrainment drying. In the case of entrainment drying of a biological product, it is usually the internal material transfer that is the limiting phenomenon. In the case of boiling drying, it is rather the heat transfer rate that limits the drying rate (Bonazzi and Bimbenet, 2003).

During baking in hot air $\left(\mathrm{T}_{a}>100^{\circ} \mathrm{C}\right)$ in an oven of products such as bread or cake dough for example, two heating periods were generally considered in the models with simultaneous heat and water transfer: (i) period of product heating to $100^{\circ} \mathrm{C}$ and (ii) period of crust and core formation (Vries et al., 1988; Zanoni et al., 1994; Sablani et al., 1998; Lostie et al., 2002; Flick et al., 2015). According to Zanoni et al. (1994), during the period (i), water is vaporized at the surface of the product and the drying rate is controlled by diffusion of liquid water from the core to the surface. During the period (ii), a water vaporization front appears at $100^{\circ} \mathrm{C}$ and moves inwards resulting in the formation of two distinct regions: the crust and the core. The drying rate during this period is controlled by heat conduction through the surface dry layer.

A strong similarity with hot air frying appears in the description of the bread baking process, despite the presence of other complex phenomena such as fermentation and the presence of gases in the bread doughs. The approaches to modeling the period (ii) during bread baking are very similar to those for deep frying.

We can cite two scientific publications about hotair frying: (Andrés et al., 2013) compares kinetics of mass transfer and volume changes in hot-air frying and deep-fat frying at $180{ }^{\circ} \mathrm{C}$; Our work (Gouyo et al., 2021a) is the only one about hot-air frying with a dynamic model, and we present here its main results.

In this study, by microstructure analysis of french fries, Gouyo et al. (2021b), the french fries were modelled as three concentric compartments in series, with heat and mass resistances at interfaces only.

\section{Materials and methods}

\subsection{Raw materials and frying equipment}

The experiments were carried out with commercial frozen pre-fried (Vauvre et al., 2014; Aguilera and Gloria-Hernandez, 2000) french fries (Mc-Cain Tradition) stored in a cold room at $-18{ }^{\circ} \mathrm{C}$. These French fries (Mccain tradition) are designed for domestic deep fat frying of 5 to 10 minutes. A primary selection of frozen french fries was done, according to (1) being straight, (2) with a square section of $9 \times 9 \mathrm{~mm}$ exactly, and (3) long enough to be resized to $60 \mathrm{~mm}$ in length with a specific cutter.

Hot-air fryer equipment (Airfryer Philips XL HD9240/90, Avance Collection, Amsterdam, The Netherlands) with a power of $2100 \mathrm{~W}$ was used. A specific fryer's control system allowed to adjust the air velocity and to add an extra radiative heating component (halogen, Suney 012072, $1000 \mathrm{~W}$ ). The air velocity was measured above the basket with an anemometer (MiniAir 64 Mini, OmniInstruments, UK). This modification allowed for three different operating conditions in terms of the intensity of energy input and the mode of input. The fryer was instrumented with a power meter (PM231 - Powermeter, brennenstuhl, CHINA) connected to the energy sources (electrical resistance and radiative heating source). The fryer was placed on a scale (Sartorius CPA34001S, France) that allowed 
recording the water loss.

In the single bed of $0.200 \mathrm{~kg}$ of french fries, the fries hardly touch each other. Triplicates were performed for each experiment.

\subsection{Temperature measurements}

Two thermocouples were inserted in the potato, either at the surface $\left(T_{S}\right)$ or at the core $\left(T_{c o}\right)$. Infrared thermometers (MLX90614KSF-ACC, Melexis, CorbeilEssonnes, France) were also used to measure the surface temperature $\left(T_{I R}\right)$. The air temperature $\left(T_{a}\right)$ away from the french fries was also measured with a type J thermocouple placed in the Airfryer.

\section{Model development}

\subsection{Justification for three compartments}

The experimental observation of frozen french fries during hot-air frying by $\mathrm{X}$-ray microtomography by Gouyo et al. (2021b) shows a central compartment with a pre-crust formed at the periphery of the frozen french fry. At the end of frying, three distinct compartments were observed: the core has shrunk while an intermediate gaseous one has appeared.

These findings split the french fries into 3 different compartments (figure 1):

1. the central compartment \#1, containing wet fatted matter, whose ice content decreases from $15 \%$ to $0 \%$, then whose temperature $T_{1}$ reaches boiling point including ebulioscopic elevation, then its water content decrease starting from $75 \%$, creating a volume shrinkage.

2. the medium compartment $\# 2$ is filled of $m_{2}$ (in $\mathrm{kg}$; initially null) of vapor possibly superheated at temperature $T_{2}$ that escapes from compartment \#1 through compartment \#3.

3. the peripheral compartment \#3 corresponds to the crust compartment formed while prefrying the french fries. It is a porous wet fatted matter, with very low water content and higher oil content.

\subsection{General assumptions}

To minimise computational effort, Gouyo et al. (2021a)'s assumptions were kept. The evolution of the different variables are summarized in Table 1 . The different successive mechanisms taken into account in the model are listed as well.

\subsection{Shrinkage of compartment \#1}

By microstructure analysis of french fries, Gouyo et al. (2021b) showed that the porosity created in the frozen french fry matched the water loss of the product. The
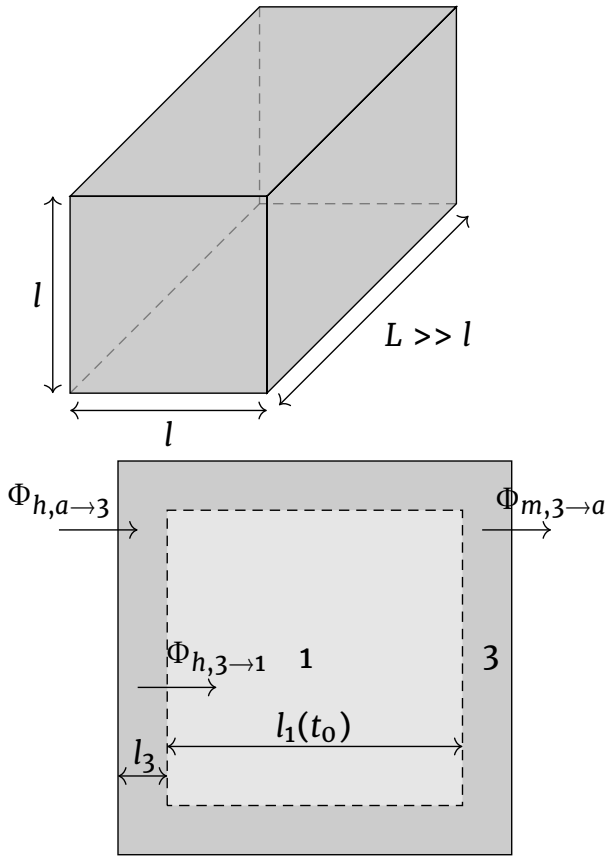

Before 1 compartment boils.

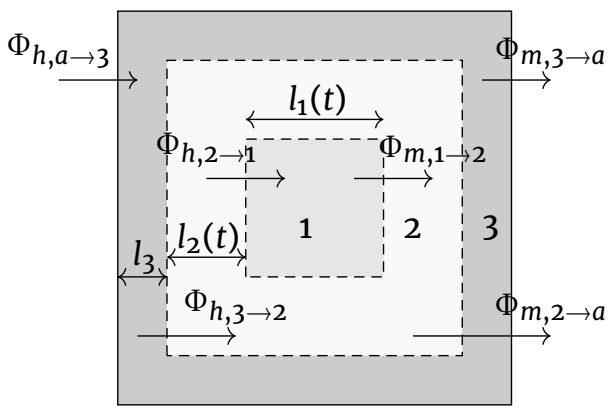

When compartment 1 boils.

Figure 1. French fries are seen as infinite rectangular parallelepiped with 3 concentric shells or compartments (the second being negligible before compartment 1 boils).

Table 1. Values and variations of state variables for compartments \#1, \#2 and \#3. $\nearrow$ : grow, \: decrease. Unless written overwise, states keep their previous values. "drying" refers to convective drying. "boiling" refers to drying by boiling.

\begin{tabular}{|c|c|c|c|}
\hline Step & \#1 & \#2 & \#3 \\
\hline warm-up \#1 and \#3 & $\mathrm{T} \nearrow ; P=P_{a}$ & $V=0$ & $T \nearrow$ \\
\hline warm-up \#1, defrost \#3 & $\mathrm{T} \nearrow$ & & $\mathrm{T}=0 ; I \searrow ; W \nearrow$ \\
\hline warm-up \#1, drying \#3 & $\mathrm{T} \nearrow$ & & $T \nearrow ; I=0 ; W \searrow$ \\
\hline defrost \#1, drying \#3 & $\mathrm{T}=0 ; I \searrow ; W \nearrow$ & & $\mathrm{T} \nearrow ; W \searrow$ \\
\hline warm-up \#1, drying \#3 & $T / \nearrow ;=0$ & & $T \nearrow ; W \searrow$ \\
\hline warm-up \#1, boiling \#3 & $\mathrm{T} \nearrow$ & & $\mathrm{T} \nearrow ; W \searrow$ \\
\hline boiling \#1 and \#3 & $\mathrm{T} \nearrow ; V, W \searrow ; P=P_{2}$ & $T, V, P, m \nearrow$ & $T \nearrow ; W \searrow$ \\
\hline
\end{tabular}


same analogy was made for the water loss in compartment \#1, as done by Gouyo et al. (2021a).

\subsection{Convective drying (boundary equations)}

Before boiling happens, water flux density (in $\mathrm{kg}$ water per second and square meters) from compartment \#3 to hot-air (shown in figure 1) is expressed as

$$
\phi_{m, 3 \rightarrow a}=k_{3, a} \cdot \frac{M_{w}}{R} \cdot\left(\frac{A w_{3} \cdot P_{v s a t}\left(T_{3}\right)}{T_{3}+273.16}-\frac{R H_{a} \cdot P_{v s a t}\left(T_{a}\right)}{T_{a}+273.16}\right)
$$

where $M_{w}$ is the molar mass of water, $R$ is the ideal gas constant, $k_{3, a}$ the mass transfer coefficient $\left(\mathrm{m} \cdot \mathrm{s}^{-1}\right)$, and where the water activity $A w$ satisfies

$$
X=\frac{14.11-5.013 \cdot 10^{-2} \cdot T}{100} \cdot\left(\frac{A w}{1-A w}\right)^{0.124+2.063 \cdot 10^{-3} \cdot T}
$$

\subsection{Boiling}

Water activity, product temperature and water content are linked by above equation (1). When boiling, they are also linked by this equation relying on ClausiusClapeyron relationship (Murray, 1967):

$$
A w \cdot P_{v s a t}(T)=P
$$

where $P_{v s a t}(T)=10^{2.7858+\frac{7.5 . T}{T+237.3}} \mathrm{~Pa}$.

At known pressure, water content and product temperature are linked by above two equations in a boiling compartment, hence their derivative are also linked (Gouyo et al., 2021a).

When compartment \#1 boils, compartment \#2 emits water vapor to air which is "filtrated" by compartment \#3 following Darcy's law (Loncin and Merson, 1979). The equation is:

$$
\phi_{m, 2 \rightarrow a}=\rho_{v} \cdot \frac{\kappa v}{\mu} \cdot \vec{\nabla} P=\rho_{v} \cdot \frac{\kappa v}{\mu \cdot l_{3}} \cdot\left(P_{2}-P_{a}\right)
$$

\subsection{Heat transfer}

Assuming convective drying, heat flux densities can be written simply as:

$$
\phi_{h, a \rightarrow 3}=h_{3, a} \cdot\left(T_{a}-T_{3}\right)
$$

Prior to compartment \#1 boiling, there is no compartment \#2 and direct heat transfer between compartment \#1 and \#3 is done by conduction:

$$
\phi_{h, 3 \rightarrow 1}=h_{1,3} \cdot\left(T_{3}-T_{1}\right)
$$

When compartment \#1 is boiling then, heat transfer is indirect, by convection through compartment \#2:

$$
\phi_{h, 2 \rightarrow 1}=h_{1,2} \cdot\left(T_{2}-T_{1}\right)
$$

$$
\phi_{h, 3 \rightarrow 2}=h_{2,3} \cdot\left(T_{3}-T_{2}\right)
$$

Note: It was assumed that $h_{1,2}=h_{2,3}$.

These equations (1)-(8) are taken from publication Gouyo et al. (2021a). This publication also details thoughfully their effect on heat and mass balances.

\subsection{Frozen condition}

Assuming no sublimation, the ice first becomes liquid water then vapour. To keep the model the simplest possible, we assumed that defrosting occured at $0^{\circ} \mathrm{C}$ while, in practice, food defrosting takes place at temperatures below $0^{\circ} \mathrm{C}$ that unfortunately depend on the solid water content. Moreover, it was assumed that no (negligible) drying occurs in a compartment \#i where ice content $I_{i}>0 . X_{i}$ is the total water content (ice+liquid water) with respect to the dry fatted matter (dry matter + oil). $I_{i}$ is the frozen water content, hence the liquid water content is equal to $W_{i}=X_{i}-I_{i}$.

\section{Results and discussion}

On Matlab (version 2017b, Mathworks, USA), simulation time was one second using $10^{10}$ bytes of memory (RAM) on a 64 bit computer with $2.30 \mathrm{GHz}$ Intel(R) Core (TM) i5-62004 CPU@ .

The identified heat and mass transfer coefficients are shown in Table 2. Available literature is scarce about mass transfer coefficient for potato products. In comparison, the identified values for $k_{3, a}$ are reasonable $\left(3.58 \cdot 10^{-3}\right.$ to $\left.4.10 \cdot 10^{-3} \mathrm{~m} \cdot \mathrm{s}^{-1}\right)$, but remain high compared to the values found in the case of conventional drying. Comparing the value of the mass transfer coefficient identified in this study to literature is difficult due to different conditions of the drying process. For instance, most authors (Miketinac et al., 1992; Białobrzewski, 2007; Dhalsamant et al., 2017) use a difference in water content in mass as the driving force for the water flux density, and the values of the mass transfer coefficient obtained are generally in the magnitude of $10^{-5}-10^{-4} \mathrm{~m} \cdot \mathrm{s}^{-1}$.

Table 2 shows that despite the different modes of heat transfer, the global heat transfer coefficients remains still quite similar. High Convection frying mode provides a higher global heat transfer coefficient (High Convection, $h_{3, a}=96 \mathrm{~W} \cdot \mathrm{m}^{-2} \cdot \mathrm{K}^{-1}$ ). The higher is $h_{3, a}$, the faster $\mathrm{T}_{3}$ reaches $100^{\circ} \mathrm{C}$ and the higher it rises at the end of the frying process (figure 2). The heat transfer coefficients obtained are extremely far from the values 
Table 2. Identified values for transfer parameters of heat $\left(h_{1,3}, h_{2,3}\right.$, $\left.h_{3, a}\right)$ and water $\left(k_{3, a}\right)$.

\begin{tabular}{llll}
\hline Parameter & Unit & Setting & Identified value \\
\hline$h_{1,3}$ & $\mathrm{~W} \cdot \mathrm{m}^{-2} \cdot \mathrm{K}^{-1}$ & All & $254 \pm 9$ \\
$h_{2,3}$ & $\mathrm{~W} \cdot \mathrm{m}^{-2} \cdot \mathrm{K}^{-1}$ & All & $202 \pm 5$ \\
$h_{3, a}$ & $\mathrm{~W} \cdot \mathrm{m}^{-2} \cdot \mathrm{K}^{-1}$ & C-Standard & $66 \pm 1$ \\
$h_{3, a}$ & $\mathrm{~W} \cdot \mathrm{m}^{-2} \cdot \mathrm{K}^{-1}$ & C-Standard-Halo & $73 \pm 1$ \\
$h_{3, a}$ & $\mathrm{~W} \cdot \mathrm{m}^{-2} \cdot \mathrm{K}^{-1}$ & High Convection & $76 \pm 1$ \\
$k_{3, a}$ & $\mathrm{~m} \cdot \mathrm{s}^{-1}$ & C-Standard & $3.70 \cdot 10^{-3} \pm 0.06 \cdot 10^{-3}$ \\
$k_{3, a}$ & $\mathrm{~m} \cdot \mathrm{s}^{-1}$ & C-Standard-Halo & $4.10 \cdot 10^{-3} \pm 0.06 \cdot 10^{-3}$ \\
$k_{3, a}$ & $\mathrm{~m} \cdot \mathrm{s}^{-1}$ & High Convection & $3.58 \cdot 10^{-3} \pm 0.20 \cdot 10^{-3}$ \\
\hline
\end{tabular}

that can be obtained in the deep-fat frying process, which can be up to $250-1000\left(\mathrm{~W} \cdot \mathrm{m}^{-2} \cdot \mathrm{K}^{-1}\right)$.

The internal transfer coefficients $\left(h_{1,3}\right.$ and $\left.h_{2,3}\right)$ are four times the external transfer coefficients $\left(h_{3, a}\right)$, proving non limiting internal heat transfer.

A wide range of values for intrinsic permeability $\kappa_{\nu}$ $\left(10^{-10}\right.$ to $\left.10^{-14}\right)$ were tested, showing negligible effects on the model predictions.

Figure 2 displays the experimental and simulated evolution of french fry temperature during frying for the differents geometrical points. The mean coefficient of variation for experimental temperature acquisition inside french fry was quite good $\left(<10^{\circ} \mathrm{C}\right)$ and rootmean-square error (RMSE) between experimental and predicted values was reasonable as well. As shown on 2 , the air temperature close to the french fries rises rapidly to $150{ }^{\circ} \mathrm{C}$, then gradually reaches $180^{\circ} \mathrm{C}$ in less than 120 seconds of cooking. The evolution of the estimated- actual surface temperature is represented by an area between the $T_{I R}$ measured by infrared and the $T_{s}$ measured by a thermocouple. The surface temperature of the french fries increases relatively rapidly due to the high initial temperature difference between the hot-air and the frozen french fries. To reach $100^{\circ} \mathrm{C}$ on the surface of the french fry, it takes 100 to 120 seconds of frying as compared to 20 seconds for deepfat frying (Achir et al., 2008; van Koerten et al., 2017). This is related to the higher heat transfert coefficient betwen oil and product.

The experimental core temperature shows a plateau around $-4^{\circ} \mathrm{C}$ at the beginning of frying, related to the core defrosting which occurs in less than $60 \mathrm{~s}$. This plateau does not fit well with the simulation data because we assumed, to keep the model the simplest possible, that defrosting occured at $0^{\circ} \mathrm{C}$. This leads to a slight mismatch in the evolution of the simulated core temperature with the experimental core temperature. This assumption leads to a mismatch on temperature prediction that becomes negligible after the initial defrosting. The temperature increase in the core compartment (compartment \#1) is delayed compared to the compartment \#3, due to the resistance to heat transfer in the crust compartment (compartment \#3). However, it reaches a value around $100{ }^{\circ} \mathrm{C}$, which is maintained due to the high latent heat of evaporation of water which is present in large amounts in the core. This boiling temperature is reached in the core after about $120 \mathrm{~s}$ of frying.

The same plateau stagnation is observed for the surface temperature, but the duration is much shorter than for the core: the temperature increase is halfed for a few seconds. The reason for this is the rapid dehydration of the external compartment \#3. When this compartment is almost dried, it can no longer serve as an energy sink and its temperature $T_{3}$ begins to rise. $\mathrm{T}_{3}$ is well below the temperature of the hot-air near to the french fries. This is because the water evaporating from deeper inside the fry still acts as a cooling source. This plateau can also be observed in the case of deep-fat frying ( $5 \mathrm{~s}$ ) but the duration of the plateau is very short compared to hot-air frying (Farid and Kizilel, 2009; Lioumbas and Karapantsios, 2012; Lalam et al., 2013; van Koerten et al., 2017).

The model predictions of the temperature for the nominal frying condition (other conditions shown by Gouyo et al. (2021a)) are also shown in the figure 2, along the measurements. Actually, the temperature evolution in both the core (compartment \#1) and the surface (compartment \#3) are reasonably predicted for all data sets.

The model predicts a plateau at $100^{\circ} \mathrm{C}$ for temperature in the compartment \#3 (Surface) for a few minutes. Non-invasive techniques (Touffet et al., 2020) showed that mechanical fractures and cracks (with cavitation) occur beneath the rigid (glassy) crust, justifying this discrepancy. The model assumes a crust thickness (compartment \#3) is $1 \mathrm{~mm}$. The state variable $T_{3}$ is therefore an average of the temperature in compartment \#3.

Analysis of predicted pressure evolution at the core of the french fry shows that $P_{2}$ is very close to $P_{a}$ (overpressure $<0.5 \mathrm{kPa}$ ). This result supports the assumption that $P_{1}=P_{a}$. During deep-fat frying, the overpressure $\Delta P_{a}$ is larger than $30 \mathrm{kPa}$ (Patsioura et al., 2016; Vauvre et al., 2014), which is way higher than what we observed in hot-air frying.

The model fitted very well the experimental mean water content. The assumption of convective drying of the compartment \#3 before boiling is relevant, allowing to fit the first drying phase.

The global shrinkage of french fries is very small (Gouyo et al., 2021b): less than $10 \%$ in both radial and longitudinal directions. Therefore the mechanical effect of heat and mass transfer was neglected. The only significant shrinkage is local and related to comparment \#1, which considers that a volume of water lost in compartment \#1 produces a shrinkage of the same volume (Gouyo et al., 2021b).

On the left of Figure 3, there is a stage (phase 1, the initial heating period) that corresponds to the rise the heating and the defrosting phase of the french 


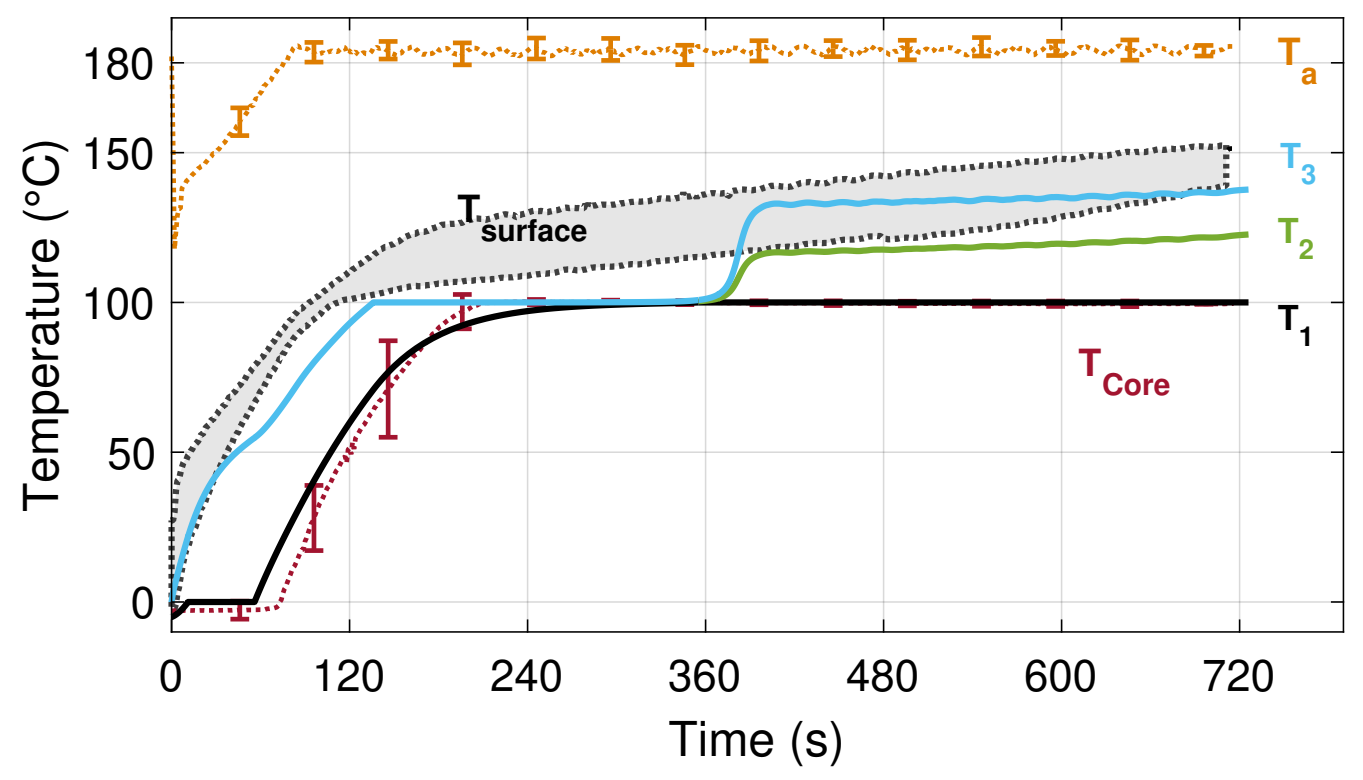

Figure 2. The measured evolution of temperatures in time plotted for the core $\left(T_{\text {core }}\right)$ and the surface of the french fries ( $\left.T_{\text {surface }}\right)$ in reference air-frying conditions. $T_{a}=$ Air temperature in the area away from the french fries and $T_{1}, T_{2}$, and $T_{3}$ correspond to the temperatures of compartment \#1, \#2 and \#3 respectively. Error bars represent twice $(2 \sigma)$ standard deviation between replicates for data (dashed lines). The solid lines represent the model predictions.

fries. During this stage, $T_{3}$ is raised to the boiling temperature of the water, after which evaporation begins. Obviously, this stage lasts more if the heat transfer coefficient $\left(h_{3, a}\right)$ is lower (observed only for the C-Standard condition). Dehydration of the product then follows, to reach a maximum around 300 to 400 s. The first dehydration slope observed on the drying curve (figure 3) corresponds to the evaporation phase in compartment \#3 and the rise in $T_{1}$. After the water of compartment \#3 has been evaporated, the temperature in compartment \#3 will exceed the boiling point of water (figure 2). The second slope corresponds to the maximum water evaporation, coinciding with the boiling phase in the compartment \#1. The rate of evaporation is at its maximum at this moment because both compartments \#1 and \#3 are boiling and there is more water in compartment \#1. The highest value of the measured vapour flow density for the different hot-air frying conditions was relatively lower (2.5 . $\left.10^{-3} \mathrm{~kg} \cdot \mathrm{m}^{-2} \cdot \mathrm{s}^{-1}\right)$ than what was found in deep-fat frying $\left(5-10 \cdot 10^{-3} \mathrm{~kg} \cdot \mathrm{m}^{-2} \cdot \mathrm{s}^{-1}\right)$ (Costa and Oliveira, 1999; Vitrac et al., 2002; Ziaiifar, 2008; van Koerten et al., 2017). Despite the different evolution of the surface temperature for the three frying conditions, the evolution of the water loss remains very close.

\section{Conclusion}

A dynamic three-compartment model including heat and vapour transfer was developed. Taking into account four major stages: defrosting, warm-up, con-

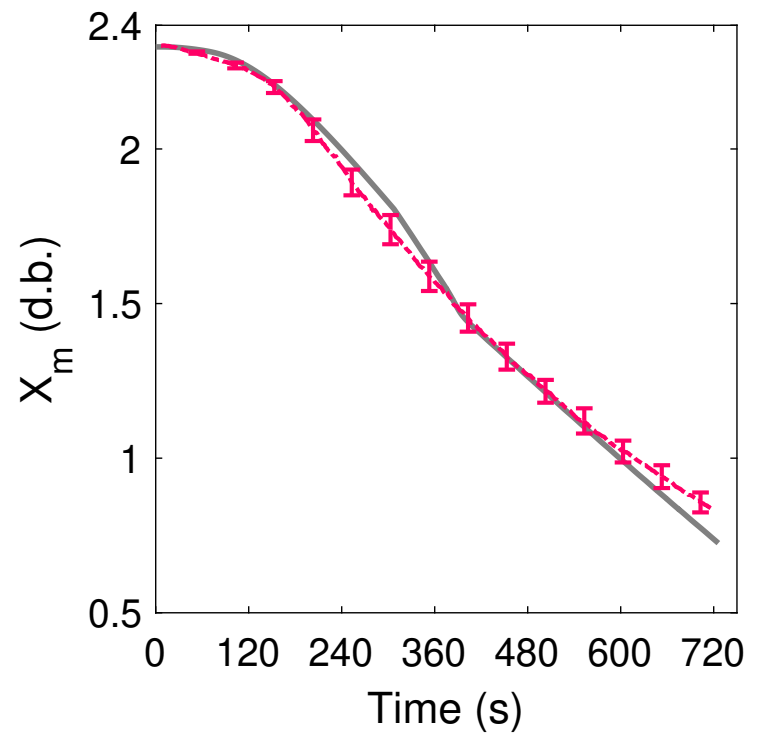

Figure 3. Water loss as function of frying time for reference frying conditions. Experimental data (.......), predictions (-). Error bars represent twice $(2 \sigma)$ standard deviation between triplicates. 
vective drying and boiling drying. A good fit was observed with the experimental data of water content and core temperature evolution during hot-air frying. The model is hence accurate to simulate hot-air frying of frozen -pre-fried- french fries at different conditions and is considered relevant for the frozen pre-fried french fries from defrosting, warming-up to convective drying and boiling drying of the crust and boiling drying of the core. In addition, it allows to study the effect of variable air characteristics and different ways of providing energy to the product. The convective heat transfer coefficient between the external compartment and the hot-air is the most sensitive. We consider it can be a promising tool for the control and optimization of hot-air frying.

\section{Acknowledgements}

The authors thank the anonymous reviewers for their welcome comments. This study was funded by SEB Group, ANRT and CIRAD Montpellier.

\section{Bibliographic references}

\section{References}

Achir, N., Vitrac, O., and Trystram, G. (2008). Simulation and ability to control the surface thermal history and reactions during deep fat frying. Chemical Engineering and Processing: Process Intensification, 47(11):1953-1967.

Aguilera, J. M. and Gloria-Hernandez, H. (2000). Oil Absorption During Frying of Frozen Parfried Potatoes. Journal of Food Science, 65(3):476-479.

Andrés, A., Arguelles, A., Castelló, M. L., and Heredia, A. (2013). Mass Transfer and Volume Changes in French Fries During Air Frying. Food and Bioprocess Technology, 6(8):1917-1924.

Białobrzewski, I. (2007). Determination of the mass transfer coefficient during hot-air-drying of celery root. Journal of Food Engineering, 78(4):1388-1396.

Bonazzi, C. and Bimbenet, J.-J. (2003). Séchage des produits alimentaires - principes.

Bouchon, P. and Aguilera, J. M. (2001). Microstructural analysis of frying potatoes. International Journal of Food Science and Technology, 36(6):669-676.

Bouchon, P. and Pyle, D. (2005). Modelling oil absorption during post-frying cooling. Food and Bioproducts Processing, 83(4):253-260.

Costa, R. M. and Oliveira, F. A. R. (1999). Modelling the kinetics of water loss during potato frying with a compartmental dynamic model. Journal of Food Engineering, 41(3):177-185.

Courtois, F., Trystram, G., Lemaire, R., and Wack, A.-L. (1998). Modelling of deep fat frying of banana using a compartmental approach and boiling's theory. In Drying'98.
Dhalsamant, K., Tripathy, P. P., and Shrivastava, S. L. (2017). Moisture transfer modeling during solar drying of potato cylinders considering shrinkage. International Journal of Green Energy, 14(2):184-195.

Farid, M. and Kizilel, R. (2009). A new approach to the analysis of heat and mass transfer in drying and frying of food products. Chemical Engineering and Processing: Process Intensification, 48(1):217-223.

Farid, M. M. and Chen, X. D. (1998). The analysis of heat and mass transfer during frying of food using a moving boundary solution procedure. Heat and Mass Transfer, 34(1):69-77.

Farkas, B. E., Singh, R. P., and Rumsey, T. R. (1996). Modeling heat and mass transfer in immersion frying. II, model solution and verification. Journal of Food Engineering, 29(2):227-248.

Flick, D., Doursat, C., Grenier, D., and Lucas, T. (2015). 5 - modelling of baking processes. In Bakalis, S., Knoerzer, K., and Fryer, P. J., editors, Modeling Food Processing Operations, Woodhead Publishing Series in Food Science, Technology and Nutrition, pages 129161. Woodhead Publishing.

Garayo, J. and Moreira, R. (2002). Vacuum frying of potato chips. Journal of Food Engineering, 55(2):181191.

Gouyo, T., Goujot, D., Bohuon, P., and Courtois, F. (2021a). Multi-compartment model for heat and mass transfer during the frying of frozen pre-fried french fries. Journal of Food Engineering, 305:110587.

Gouyo, T., Rondet, E., Mestres, C., Hofleitner, C., and Bohuon, P. (2021b). Microstructure analysis of crust during deep-fat or hot-air frying to understand French fry texture. Journal of Food Engineering, 298:110484.

Gupta, P., Shivhare, U. S., and Bawa, A. S. (2000). Studies on frying kinetics and quality of french fries. 18(1):311-321.

Heredia, A., Castelló, M. L., Argüelles, A., and Andrés, A. (2014). Evolution of mechanical and optical properties of French fries obtained by hot air-frying. LWT - Food Science and Technology, 57(2):755-760.

Krokida, M. K., Oreopoulou, V., Maroulis, Z. B., and Marinos-Kouris, D. (2001). Deep fat frying of potato strips-quality issues. 19(5):879-935.

Lalam, S., Sandhu, J. S., Takhar, P. S., Thompson, L. D., and Alvarado, C. (2013). Experimental study on transport mechanisms during deep fat frying of chicken nuggets. LWT - Food Science and Technology, 50(1):110119.

Lioumbas, J. S. and Karapantsios, T. D. (2012). Effect of Potato Orientation on Evaporation Front Propagation and Crust Thickness Evolution during Deep-Fat Frying. Journal of Food Science, 77(10):E297-E305.

Loncin, M. and Merson, R. L. (1979). Food engineering, principles and selected applications. Academic Press, New York.

Lostie, M., Peczalski, R., Andrieu, J., and Laurent, M. 
(2002). Study of sponge cake batter baking process. part i: Experimental data. 51(2):131-137.

Miketinac, M., Sokhansanj, S., and Tutek, Z. (1992). Determination of heat and mass transfer coefficients in thin layer drying of grain. Transactions of the American Society of Agricultural Engineers, 35(6):1853-1858. cited By 47.

Murray, F. W. (1967). On the computation of saturation vapor pressure. Journal of Applied Meteorology, 6(1):203-204.

Ni, H. and Datta, A. (1999). Moisture, oil and energy transport during deep-fat frying of food materials. Food and Bioproducts Processing, 77(3):194-204.

Patsioura, A., Vauvre, J.-M., Kesteloot, R., Smith, P., Trystram, G., and Vitrac, O. (2016). Chapter 17 Mechanisms of Oil Uptake in French Fries. In Singh, J. and Kaur, L., editors, Advances in Potato Chemistry and Technology (Second Edition), pages 503-526. Academic Press, San Diego.

Pedreschi, F. and Aguilera, J. M. (2002). Some changes in potato chips during frying observed by confocal laser scanning microscopy (CLSM). Food Science and Technology International, 8(4):197-201.

Sablani, S. S., Marcotte, M., Baik, O. D., and Castaigne, F. (1998). Modeling of simultaneous heat and water transport in the baking process. 31(3):201-209.

Sansano, M., Juan-Borrás, M., Escriche, I., Andrés, A., and Heredia, A. (2015). Effect of Pretreatments and Air-Frying, a Novel Technology, on Acrylamide Generation in Fried Potatoes. Journal of Food Science, 80(5):T1120-T1128.

Teruel, M. R., Gordon, M., Linares, M. B., Garrido, M. D., Ahromrit, A., and Niranjan, K. (2015). A comparative study of the characteristics of french fries produced by deep fat frying and air frying. Journal of Food Science, 80(2):E349-E358.

Tian, J., Chen, S., Shi, J., Chen, J., Liu, D., Cai, Y., Ogawa, Y., and Ye, X. (2017). Microstructure and digestibility of potato strips produced by conventional frying and air-frying: An in vitro study. Food Structure, 14:30-35.

Touffet, M., Trystram, G., and Vitrac, O. (2020). Revisiting the mechanisms of oil uptake during deep-frying. Food and Bioproducts Processing, 123:14 - 30.

van Koerten, K. N., Somsen, D., Boom, R. M., and Schutyser, M. A. I. (2017). Modelling water evaporation during frying with an evaporation dependent heat transfer coefficient. Journal of Food Engineering, 197:60-67.

Vauvre, J.-M., Kesteloot, R., Patsioura, A., and Vitrac, O. (2014). Microscopic oil uptake mechanisms in fried products. European Journal of Lipid Science and Technology, 116(6):741-755.

Vitrac, O., Dufour, D., Trystram, G., and Raoult-Wack, A.-L. (2002). Characterization of heat and mass transfer during deep-fat frying and its effect on cassava chip quality. Journal of Food Engineering,
53(2):161-176.

Vries, U. d., Sluimer, P., Bloksma, A. H., and Centraal Instituut voor Voedingsonderzoek TNO (1988). A quantitative model for heat transport in dough and crumb during baking. Series Number: 600 .

Xiong, X., Narsimhan, G., and Okos, M. R. (1992). Effect of composition and pore structure on binding energy and effective diffusivity of moisture in porous food. Journal of Food Engineering, 15(3):187-208.

Yamsaengsung, R. and Moreira, R. G. (2002). Modeling the transport phenomena and structural changes during deep fat frying: Part I: model development. Journal of Food Engineering, 53(1):1-10.

Zanoni, B., Pierucci, S., and Peri, C. (1994). Study of the bread baking process - II. mathematical modelling. 23(3):321-336.

Ziaiifar, A. M. (2008). Mécanisme d'imprégnation en huile au cours de friture. thesis, Paris, AgroParisTech. 